\title{
Optic nerve injury in fracture of the canal
}

\author{
J. H. RAMSAY \\ From the Ophthalmology Department, Guy's Hospital, St Thomas Street, London SE1 9RT
}

SUMmARY A case of unilateral blindness following blunt injury to the skull is presented. The patient died 4 days after the initial injury, presenting the rare opportunity of a detailed histopathological study of the acute features of the condition. The findings are discussed in the context of current theories of the pathogenesis of optic nerve injury in fractures of the optic canal.

Unilateral visual loss following closed head injury has attracted considerable attention, but this is only in part a reflection of the devastating effect on vision that injury of this type can have. Despite the accumulation of much information the exact pathogenesis of canalicular optic nerve injury remains largely a matter for speculation. The reason for this lies in the very nature of head injury; the patient either survives, allowing only clinical documentation, or dies without regaining consciousness, allowing only histopathological documentation. It is not surprising, therefore, that there is an almost complete absence of material allowing clinicopathological correlation.

The author takes the opportunity of presenting a case of optic nerve injury in which clinicopathological correlation was possible.

\section{Case report}

A previously healthy 72-year-old woman was struck by a motor vehicle on the left side of her body and head while crossing the road. She lost consciousness instantly. When she regained full consciousness in the hospital casualty department approximately 30 minutes after the accident she found that the left eye was blind.

A general examination showed multiple skin abrasions on the left side of the body and forehead. There was evidence of a left Pott's fracture and a fracture of the right pubic ramus.

Ophthalmological examination confirmed that there was no perception of light in the left eye. The right vision was 6/6 unaided with a full field. Apart from a discrete subconjunctival haemorrhage there was no evidence of direct injury to the left globe. The orbital margin was intact, and there was no displacement of the globe. Ocular movements were

Correspondence to J. H. Ramsay, FRCS. full. There was a complete afferent pupil defect on the left, but a normal consensual reaction. Fundal examination showed a normal optic disc and retina. The central retinal artery pressure appeared normal on digital pressure.

A neurological examination revealed no abnormality. No fracture was seen on plain $x$-rays of the skull and orbits. A more detailed radiological examination of the orbits and optic canals was not possible owing to her multiple injuries.

On the third day she developed a hypostatic pneumonia and died the following day.

At necropsy the brain showed numerous haemorrhages on the surface of the left cerebral hemisphere. A small linear epidural haematoma indicated an isolated fracture involving the left lesser wing of the sphenoid (Fig. 1). By stripping the dura from the entire cranial cavity it was clear that the fracture did not form part of a larger system of fractures. The left optic nerve appeared grossly intact, but there were scattered superficial haemorrhages where it emerged from the optic canal.

A block of bone, including the posterior segments of both orbits, both optic canals, and both optic nerves and chiasm, was removed in one piece. The specimen was examined macroscopically and it was noted that the fracture extended medially through the body of the sphenoid and involved the posterior part of the left posterior ethmoid sinus.

The entire specimen was fixed in formol saline. In order to complete the radiological examination the fixed specimen was immersed in a saline bath. Plain $x$-rays of the left optic foramen and horizontal hypocycloidal axial tomography were performed. It was not possible to demonstrate the fracture by either of these methods. The specimen was decalcified and a portion, including the left optic canal and nerve, was embedded in paraffin wax. This was cut into 4 blocks, and sections were cut at various 


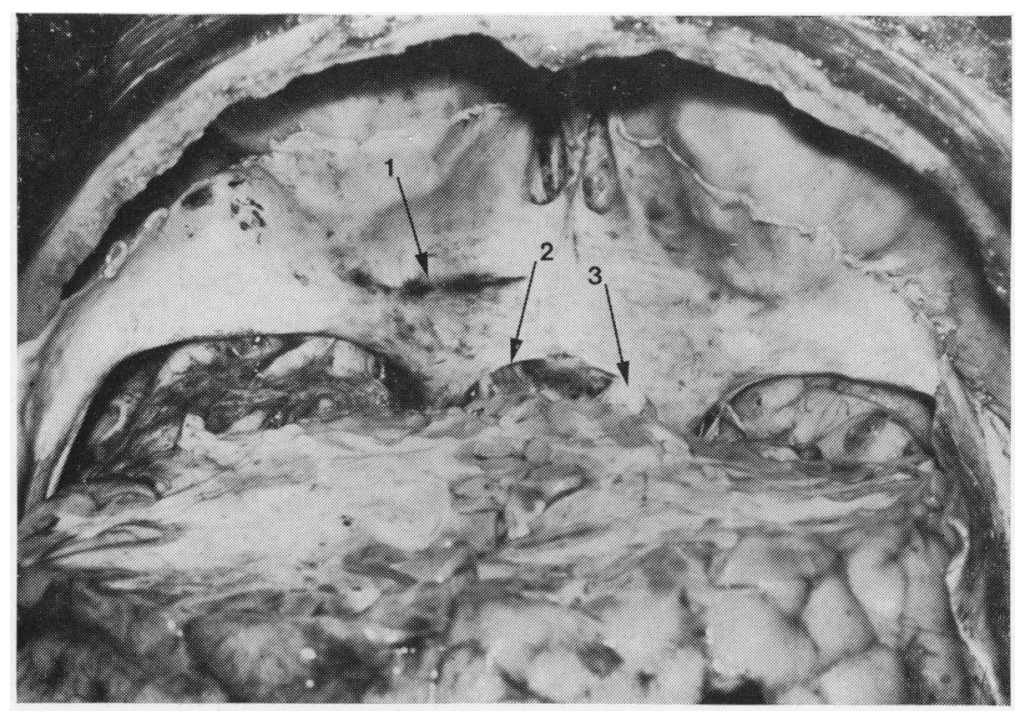

Fig. 1 Coronal view of anterior cranial fossa. (1) Linear epidural haemorrhage marking fracture line. (2) Left optic nerve emerging from canal and showing superficial haemorrhages. (3) Normal right optic nerve

levels throughout each block and stained with haematoxylin and eosin.

Microscopic examination showed that in the region of the fracture there was a well localised epidural haemorrhage on the cranial surface of the optic canal. There was only minimal haemorrhage into the dura lining the canal and no gross physical disruption of the sheath or of the nerve in that region. From a level approximately $1 \mathrm{~mm}$ anterior to the fracture line and extending posteriorly to about $3 \mathrm{~mm}$ posterior to the cranial opening of the canal the nerve was totally infarcted, showing scattered haemorrhages and neutrophil infiltration (Figs. 2, 3). At no level was it possible to identify rupture of small arterioles within the nerve or sheath.

\section{Discussion}

Two important points arise from the radiological and histopathological investigations. Firstly, despite the prior knowledge of the position and orientation of the fracture it was not identified by any of the radiological techniques used. Secondly, the absence of physical disruption of the nerve contrasted with its total infarction.

The reported incidence of radiologically identifiable fractures of the optic canal in indirect injuries of the optic nerve varies considerably. Hoffman (1935) identified a fracture in all of an undisclosed number of cases, Rollet (1930) in 80\%, Landolt (1955) in $79 \%$, Davidson (1938) in $78 \%$. In contrast Turner (1943), even with special foraminal views, identified a fracture in only 4 out of 37 cases, and Hooper (1951) was unable to detect a fracture in

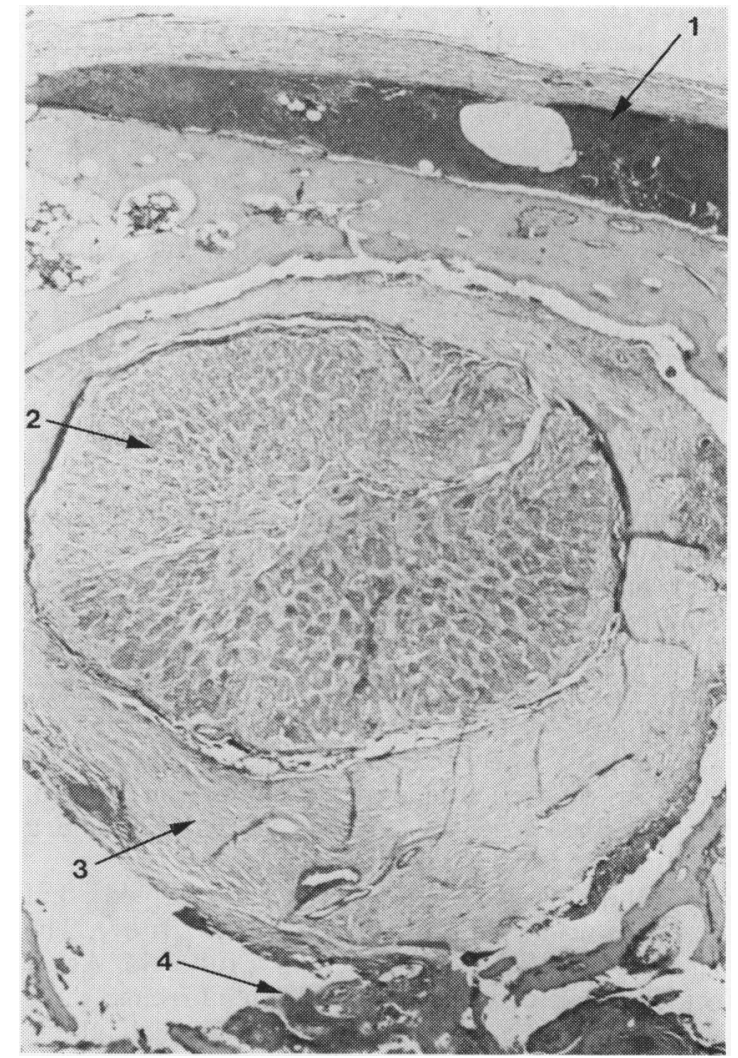

Fig. 2 (1) Epidural haemorrhage on cranial surface of optic canal. (2) Totally infarcted optic nerve. (3) Intact sheath. (4) Haemorrhage marking fracture site. $\times 65$ 


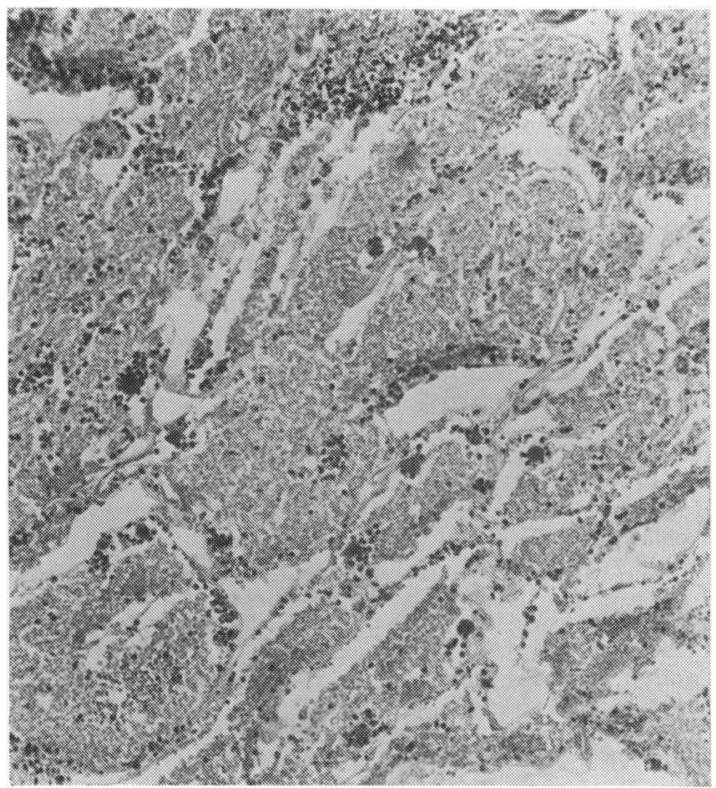

Fig. 3 High power view of nerve. $\times 385$

any of the 24 cases he examined. In a group of 56 cases in which the clinical features strongly suggested a canalicular optic nerve injury Hughes (1962) was able to detect a fracture of the optic canal in only $6 \%$.

Evidence that fractures of the canal may exist where they cannot be detected radiologically comes in reports of cases of late callus formation (Lillie and Adson, 1934) and from the relatively few cases that come to surgery. Lazorthes quoted in Hotte (1970) noticed 2 previously undetected fractures out of 6 cases and Imachi (1967) 16 out of 80 cases.

In the case described the inability to detect the fracture even tomographically with prior knowledge of the position and orientation of the fracture serves to underline the unreliability of radiographical evidence.

In a post-mortem study of 70 patients who died from head injury Walsh and Lindenberg (1963) described lesions of the optic nerves ranging from haemorrhages into the nerve and sheath and oedema of the nerve to contusion necrosis and infarction. They felt that primary contusion necrosis, which they believed resulted from the shearing force on the nerve, and secondary localised necrosis (resulting from damage to small nutrient vessels in the canalicular and intracranial portion of the optic nerve) were of prime importance.

In a review of the clinical, operative and post mortem features of 90 cases of optic nerve injury observed personally Hughes (1962) described 56 cases in which there was evidence of optic nerve injury in the absence of evidence of damage to the chiasm or to the central retinal arterial circulation. These he described as "canalicular optic nerve injuries', though clearly injuries causing severance of nerve fibres at the point of emergence of the nerve into the cranial cavity as described by Seitz (1963) must also fall into this group. Of these cases those that showed some recovery of vision tended to show altitudinal hemianopias. Similar field defects were also found among 78 cases described by Otradovec (1968). Hughes considered that an altitudinal hemianopia was evidence of a vascular aetiology, as such defects were 'found almost exclusively in vascular lesions of the optic nerve following gastrointestinal haemorrhage, thrombosis in tumours and arteriosclerotic optic atrophy.' However, it should be said that the majority of 'vascular' optic nerve lesions occur around the optic nerve head, a region of the nerve with a blood supply not typical of the rest of the nerve (Hayreh, 1974). In Hughes's series only 2 cases of suspected canalicular optic nerve injury were examined histologically. In neither case had there been any recovery of vision. One was explored 10 days after the injury, and, although the intracranial and posterior orbital portions of the nerve appeared normal, on deroofing the canal a portion of the nerve was found to be completely replaced by debris and blood clot. Unfortunately it is not clear whether there was evidence of optic canal fracture. In the second case examined at necropsy 21 days after the injury there was a fracture of the anterior fossa isolating the optic canal and anterior clinoid. The nerve showed no external abnormalities. In both cases microscopic examination showed a complete infarction of the nerve. Hughes concludes that it is insufficient to explain canalicular optic nerve injury in the majority of cases simply on the basis of the physical injury to the nerve at the fracture site, though clearly such injury can occur. Like Walsh, Hughes suggests that the vessels supplying the nerve within the canal are damaged, so that all or part of the nerve is deprived of its blood supply.

In the case described in this paper the infarction of the nerve might have arisen in 2 ways. The shearing force at the fracture site might have caused the rupture of a small arteriole supplying the nerve, resulting in the infarction of a segment of the nerve, the consequent haemorrhage and oedema in that area compressing the nerve within the canal and causing an extension of the infarction to involve the whole of the nerve. Alternatively, the shearing force, although insufficient to cause physical disruption of the nerve or sheath, might result in oedema nd precipitate the infarction through compression. 
In the sections examined no evidence was found suggesting the rupture of a feeder arteriole in the region of the fracture. It seems more likely, therefore, that in the case under consideration the infarction resulted from the compressive effect of a generalised oedema of the nerve and sheath in the region of the fracture. The fact that the area of the infarction of the nerve extended posteriorly from the fracture site for a far greater distance than it did anteriorly can be explained in terms of the blood supply to the canalicular portion of the optic nerve. Steele and Blunt (1956), Hayreh (1962), and François and Fryczkowski (1978) demonstrated in post-mortem specimens that the canalicular portion of the optic nerve was supplied by a variable number of collateral pial branches arising from the ophthalmic artery within the orbit. These vessels or their branches could thus be compressed as they passed posteriorly through the region of the fracture.

In the case presented it is not possible to decide whether the shearing force of the initial injury caused some axoplasmic disruption, which by itself would have been sufficient to cause a complete loss of vision, independent of the effect of the infarction. In those cases where a return of vision is recorded following a radiologically identifiable fracture it is possible that the oedema at the fracture site was insufficient to trigger the infarction of the entire nerve and that the initial visual loss reflected a degree of axoplasmic disruption. It is difficult to see how this theory can be put to the test until the opportunity arises to study further cases similar to the one described but in which there was a return of vision before death.

I am greatly indebted to Dr R. D. Hoare, of Guy's Hospital, and Dr G. A. S. Lloyd, of Moorfields Eye Hospital, for their advice in planning the post-mortem radiology and for their interpretation of the films, and to Dr D. R. Turner, of Guy's Hospital, for his help in the preparation and interpretation of the histological sections.

\section{References}

Davidson, M. (1938). The indirect trauma atrophies. American Journal of Ophthalmology, 21, 7-21.

François, J., and Fryczkowski, A. (1978). The blood supply of the optic nerve. Advances in Ophthalmology, 36, 164173.

Hayreh, S. S. (1962). The ophthalmic artery. III. Branches. British Journal of Ophthalmology, 46, 212-247.

Hayreh, S. S. (1974). Anterior ischaemic optic neuropathy. I. Terminology and Pathogenesis. British Journal of Ophthalmology, 58, 955-963.

Hoffman, W., and Loepp, W. (1935). Der Wert der Röntgenundersuchung bei Verletzungen der Augenhöhle. Albrecht von Graefes Archiv für Ophthalmologie, 134, 82-111.

Hooper, R. S. (1951). Orbital complications of head injury. British Journal of Surgery, 39, 126-138.

Hughes, B. (1962). Indirect injury of the optic nerves and chiasma. Bulletin of Johns Hopkins Hospital, 111, 98-126.

Imachi, Y. (1967). Clinical and pathohistological investigations of the optic nerve lesions caused by head injuries. Acta Societatis Ophthalmologicae Japonicae, 71, 18741908.

Landolt, E. (1955). Zur Opticuschädigung bei Schädeltrauma. Acta Neurochirurgica, 4, 128-142.

Hotte, H. H. A. (1970). Orbital Fractures, 1st edn., p. 201. Van Gorcum: N.V. Assen.

Lillie, W. I., and Adson, A. W. (1934). Unilateral central and annular scotoma produced by callus from fracture extending into optic canal. Transactions of the Section of Ophthalmology, Journal of the American Medical Association, 85, 90.

Otradovec, J. (1968). Das Gesichtsfeld bei indirekten Sehnervenverletsungen. Klinische Monatsblätter für Augenheilkunde, 153, 485-495.

Rollet, J., Paufique, J., and Levy, A. (1930). Les fractures du canal optique. Archives d'Ophthalmologie, 47, 737-763.

Seitz, R. (1963). Ätiologie und Genese der akuten Erblindung als Folge stumpfer Schädelverletzungen. Klinische Monatsblätter für Augenheilkunde, 143, 414-429.

Steele, E. J., and Blunt, M. J. (1956). The blood supply of the optic nerve and chiasm in man. Journal of Anatomy, 90, 486-493.

Turner, J. W. A. (1943). Indirect injuries of the optic nerve. Brain, 66, 140-151.

Walsh, F. B., and Lindenberg, R. (1963). Die Veränderungen des Sehnerven bei Indirektem Trauma. In Entwicklung und Fortschritt in der Augenheilkunde. Ferdinand Enke: Stuttgart. 